\section{Endangered Spanish science}

SIR - We should like to respond to Javier Garcia-Guinea (Nature 379, 109; 1996). He says there are two kind of scientists in Spain, those who publish in journals ranked in the Science Citation Index (SCI) and what he calls "parallel scientists". He complains that the latter are denied grants or receive less funding and respect than their counterparts. And he says that they "... publish in serious Spanish journals that are not in the $S C I$ lists. They often know French and German (rather than English) and carry out other activities such as teaching, writing books, organizing meetings or running laboratories."

Most of the "serious" Spanish journals are not refereed journals in the accepted sense; the publisher, editorial board, referees and authors belong to the same small group of people. What makes a good journal is not whether it is written in English or Spanish but that publication is restricted to high quality papers.

As far as the language itself is concerned, for all the disciplines Garcia mentions, the most important papers and the leading journals are published in English. So how can researchers who cannot understand English know what is happening in their fields? And how can they communicate their exciting findings to the international scientific com- munity? Science in the twentieth century consists not only of gathering exciting data or doing good experiments, but sharing the results in a common effort. We understand the deficiencies in the Spanish educational system, which only lately has been able to acknowledge the importance of English as the official language of science; true ignorance comes not from not knowing something but from not recognizing the need to learn.

Finally, the SCI scientists also teach (although perhaps less than the parallel ones), write books or book chapters (most of them in English, internationally distributed), organize international meetings and run laboratories (which are increasingly joined by researchers from other countries).

In Spain, as in any other country, there are two kinds of scientists, bad and good. Many of us are training abroad, trying to do quality research and facing now the uncertainties of an increasingly saturated job market. Many of us have tried to join Spanish institutions only to find the doors closed because we publish in $S C I$ journals but do not have teaching experience. (The undergraduate and graduate training that we supervise counts for nothing.) Many of us know nobody among the parallel scientists who still govern many Spanish institutions, and thus need to live with our heart in one place and our brains and hands in another. For us, the hope that mediocrity will be banished from Spanish science and that quality criteria will direct scientific policies is the only thing left.

\section{Rosa Carballada}

Cristina Hernández-Munain

Carlos Suñe-Negre

Duke University Medical Center,

Durham, North Carolina 27710, USA

SIR - Recent correspondents have drawn attention of the problems of Spanish scientists and the uncertain future. This is a sad paradox : between 1982 and 1992, "the rise in scientific production in Spain has been disproportionately greater than in the rest of the world" (F. J. Ayala, Politica Científica, 43, 5-12; 1995). This increase has been largely the work of young scientists with postdoctoral training in foreign institutions. They are now returning to Spanish institutes under 3-year contracts to carry out particular tasks within continuing projects. Some 600 young scientists now have these 3 -year contracts. They may account for 20-30 per cent of researchers in some flagship institutes of the Spanish Council for Scientific Research (CSIC).

Because the first opportunity to hire postdocs arose in 1992, some of these highly qualified researchers have now finished their contracts and are facing an uncertain

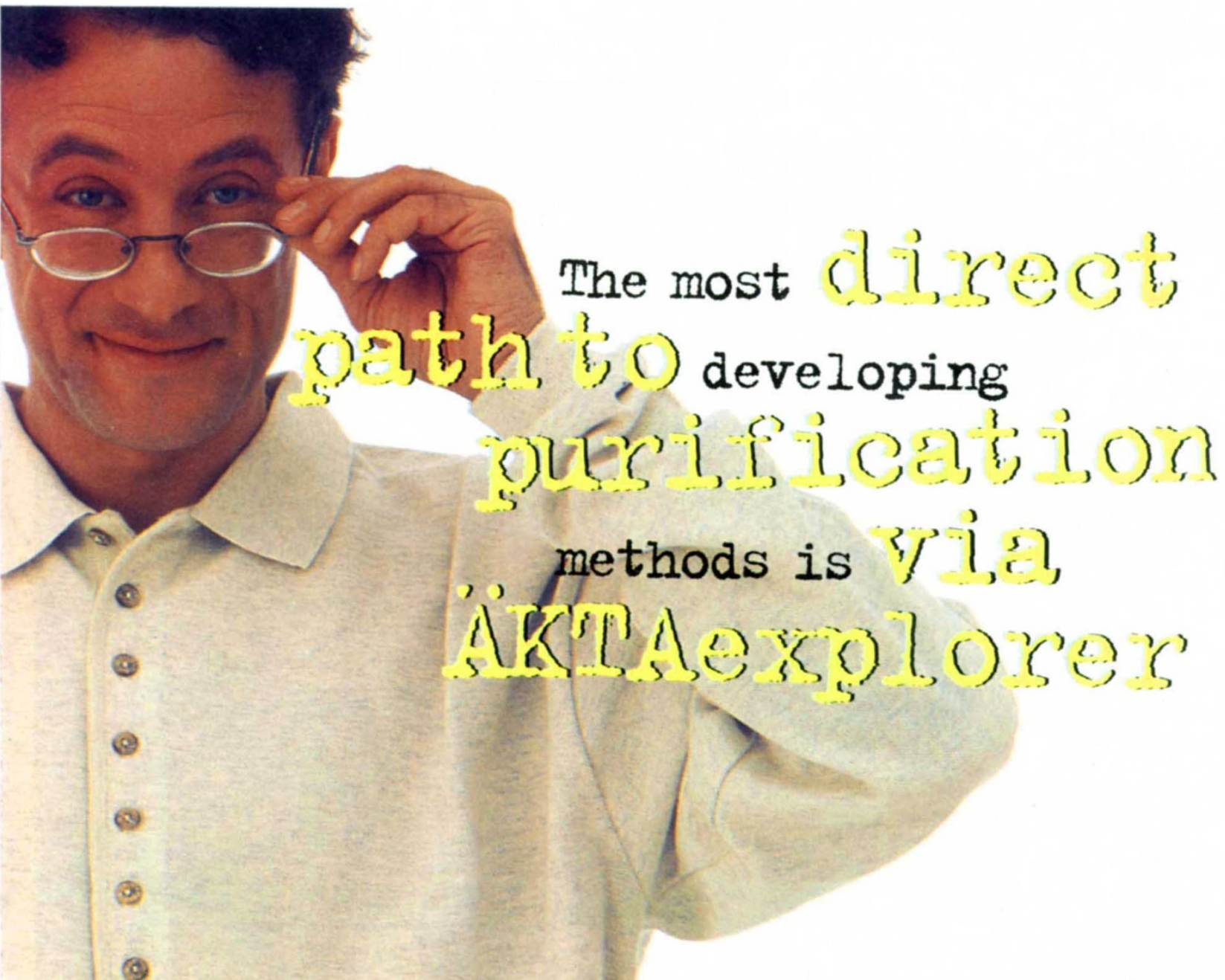

